\title{
Cryptosporidium scophthalmi n. sp. (Apicomplexa: Cryptosporidiidae) from cultured turbot Scophthalmus maximus. Light and electron microscope description and histopathological study
}

\author{
P. Alvarez-Pellitero ${ }^{1, *}$, M. I. Quiroga ${ }^{2}$, A. Sitjà-Bobadilla ${ }^{1}$, M. J. Redondo ${ }^{1}$, \\ O. Palenzuela ${ }^{1}$, F. Padrós ${ }^{3}$, S. Vázquez ${ }^{2}$, J. M. Nieto ${ }^{2}$ \\ ${ }^{1}$ Instituto de Acuicultura Torre de la Sal, Consejo Superior de Investigaciones Científicas, Ribera de Cabanes, \\ 12595 Castellón, Spain \\ ${ }^{2}$ Departamento de Ciencias Clínicas Veterinarias, Facultad de Veterinaria, Universidad de Santiago, Campus Universitario, \\ 27002 Lugo, Spain \\ ${ }^{3}$ Servicio de Diagnóstico Patológico en Peces. Facultat de Veterinària, Universitat Autònoma de Barcelona, Bellaterra, \\ 08193 Barcelona, Spain
}

\begin{abstract}
Cryptosporidium scophthalmin. sp. is described from the turbot Scophthalmus maximus L., sampled from different farms on the coast of NW Spain. The parasite was found mainly in the intestinal epithelium and very seldom in the stomach. Oocysts were almost spherical, with 4 naked sporozoites and a residuum, and measured 3.7-5.03 × 3.03-4.69 $\mathrm{mm}$ (mean $4.44 \times 3.91$ ) (shape index 1.05-1.34, mean 1.14). Sporulation was endogenous, as fully sporulated oocysts were found within the intestinal epithelium, lumen and faeces. Merogonial and gamogonial stages were in the typical extracytoplasmic position, whereas sporogonial stages were deep within the epithelium. Oocysts and other stages of C. scophthalmi comply with most of the diagnostic features of the genus Cryptosporidium, but differ from all hitherto described species. Ultrastructural features, including the characteristic feeding organelle, were mainly comparable with those of other Cryptosporidium species. Mitochondria were frequently observed in sporozoites. Infection prevalence was very variable, and juvenile fish were most frequently and intensively parasitised. External clinical signs were not detected, although some fish showed intestinal distension at necropsy. The marked histopathological damage occurring in severe infection includes distension of epithelial cells by large vacuoles, containing clusters of oocysts, and can lead to sloughing of epithelial cell remnants and oocysts or even detachment of intestinal mucosa. An inflammatory reaction involving leucocyte infiltration was sometimes observed.
\end{abstract}

KEY WORDS: Cryptosporidium scophthalmi n. sp. · Coccidia • Ultrastructure · Histopathology · Teleostei · Aquaculture

Resale or republication not permitted without written consent of the publisher

\section{INTRODUCTION}

Cryptosporidium is a genus of intracellular parasite protozoans infecting epithelial cells of the gastrointestinal and respiratory tracts of a wide variety of vertebrates, including humans. In mammals, Cryptosporidum spp. primarily infect the intestine, and clinical features include watery diarrhoea, dehydration, weight loss and even mortality (de Graaf et al. 1999, Laurent et al. 1999). The infection is self-limiting, except in immunodeficient hosts, in which it may cause protracted and untreatable diarrhoea (O'Donogue 1995, Dillingham et al. 2002, Tzipori \& Ward 2002). In farm animals, there are numerous reports of cryp- 
tosporidiosis, mainly involving members of the $C$. parvum group (de Graaf et al. 1999, Sréter \& Varga 2000). Different aspects of the host/parasite relationships have been extensively studied for members of this genus affecting economically important mammalian or avian hosts. This is in contrast to the scanty knowledge on poikiloterm and specially piscine Cryptosporidium spp. (Fayer et al. 1997). Records of Cryptosporidium spp. in wild, cultured, freshwater and marine fishes include those of Hoover et al. (1981), Pavlásek (1983), Camus \& López (1996), Paperna \& Vilenkin (1996) and Muench \& White (1997) (see also reviews of Fayer et al. 1997, 2000 and Xiao et al. 2000). Some of these lacked specific assignment. In addition, a new species Cryptosporidium molnari from farm Sparus aurata and Dicentrarchus labrax has recently been described (Alvarez-Pellitero \& Sitjà-Bobadilla 2002), and experimental transmissions have also been carried out (SitjàBobadilla \& Alvarez-Pellitero 2003). However, little is known about the host range of the piscine species in question, or about their impact on cultured fishes. Information is also lacking on a possible human and animal health threat by these waterborne parasites.

The turbot Scophthalmus maximus is one of the primary marine fishes farmed in Europe, and its intensive cultivation can be endangered by various pathogens. In the present paper, a new Cryptosporidium species parasitising the intestinal epithelium of this fish is described from light and electron microscope studies. The species is named C. scophthalmi. Pathologic findings associated with this intestinal cryptosporidiosis are given.

\section{MATERIALS AND METHODS}

Fish. From 1997 to 2000 a parasitological survey was carried out in different turbot farms in NW Spain, involving more than 800 fish. Periodical and occasional samplings were performed in hatchery, nursery and grow-out systems. Fish length and weight ranged from 5 to $26.6 \mathrm{~cm}$ and 4 to $2230 \mathrm{~g}$, respectively. Growing fish were cultured in land-based facilities receiving a flowthrough seawater supply (37\% salinity) from a pump ashore. Fish were held in $160 \mathrm{~m}^{2}$ raceways, or round $600 \mathrm{l}$ tanks, at a stocking density of about $25 \mathrm{~kg} \mathrm{~m}^{-2}$. In addition, 10 broodstock fish (weight 4000 to $7500 \mathrm{~g}$ ) and 20 fish grown in offshore cages $(1500 \mathrm{~g})$ were examined.

Turbots were sacrificed by chilling on ice and spinal cord severance or by overexposing to the anaesthetic MS-222 (Sigma). The fish were weighed, measured and necropsied, and their organs were excised for fresh and histological examination for parasites. Scrapings of intestinal mucosa and faeces were air-dried, fixed in absolute methanol and stained with Giemsa for oocyst examination.
Microscopic examination and histological procedure. For histological study, tissue portions were fixed in $10 \%$ buffered formalin and embedded in paraffin or Technovit-7100 resin (Heraeus, Kulzer). Paraffin sections (4 to $5 \mu \mathrm{m}$ ) were stained with hematoxylin-eosin, Giemsa, Ziehl-Nielsen and periodic acid Schiff (PAS) staining, and resin sections (1 to $3 \mu \mathrm{m}$ ) with toluidine blue, Giemsa and PAS staining.

For transmission electron microscope (TEM) examination, small pieces of intestine were fixed in $2.5 \%(\mathrm{v} / \mathrm{v})$ glutaraldehyde in $0.1 \mathrm{M}$ cacodylate buffer ( $\mathrm{pH} 7.2$ ), for $1 \mathrm{~h}$ at $4^{\circ} \mathrm{C}$. Samples were washed several times with the same buffer, postfixed in $1 \%$ (v/v) cacodylic $\mathrm{OsO}_{4}$, dehydrated through a graded ethanol series, and embedded in Spurr's or Epon resins. Ultrathin sections were double-stained with uranyl acetate and lead citrate. The specimens were studied in Philips CM-20 and Hitachi800 transmission electron microscopes, operating at 80 to $100 \mathrm{kV}$. For scanning electron microscopy (SEM), tissue samples were dehydrated through a graded series of ethanol, subjected to critical-point drying and observed with a Leo-435VP microscope.

All measurements were obtained from digital images taken with the software provided with a Spot camera (Diagnostic Instruments).

Statistical analysis. The length, width and shape index (length to width ratio) of oocysts measured from histological sections were compared with those available for Cryptosporidium molnari using 1-way ANOVA followed by Dunn's method. Values were considered significantly different at $\mathrm{p} \leq 0.05$.

\section{RESULTS}

\section{Description of Cryptosporidium scophthalmi}

Diagnosis. (All measurements in $\mu \mathrm{m}, \bar{x} \pm \mathrm{SD}$ ). Subspherical oocysts 3.7-5.03 $\mu \mathrm{m}(4.44 \pm 0.34) \times$ $3.03-4.69 \mu \mathrm{m}(3.91 \pm 0.41)(\mathrm{n}=49)$, with distinct colourless wall, and located in the middle or basal zones of the intestinal epithelium (Figs. 1 to 6). Longitudinal suture visible in histological sections, mainly with PAS staining (Figs. $5 \& 6$ ). Oocyst residuum generally in central position, variable in size according to maturation stage, consisting of several strong PAS-positive granules (Figs. $5 \& 6$ ). In each oocyst, there are 4 naked, elongated, vermiform, and slightly curved sporozoites with nucleus at their wider ends. Measurements of excysted sporozoites taken from histological sections ranged from 3.3-5.05 $\mu \mathrm{m}(4.02 \pm 0.41) \times$ $1.08-1.41 \mu \mathrm{m}(1.23 \pm 0.10)(\mathrm{n}=27)$. All parasite stages were visible with light microscopy. Merogonial stages line intestinal epithelium. Trophozoites or initial meronts are $1.3-3.2 \times 1.3-2.9 \mu \mathrm{m}$ (Figs. $7 \&$ 8). Meronts, 


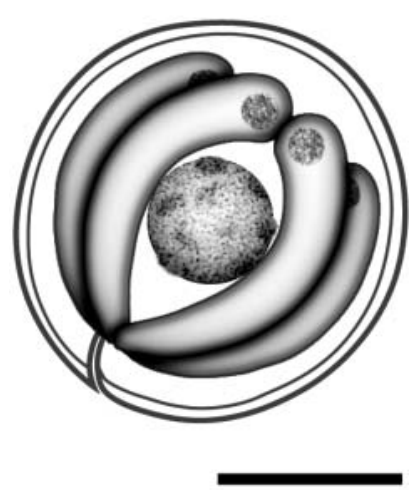

Fig. 1. Cryptosporidium scophthalmi. Line drawing of oocyst. $($ Scale bar $=2 \mu \mathrm{m})$

sometimes with dividing or divided merozoites are 2.9-4 $\times 2.9-3.8 \mu \mathrm{m}$. Type I meronts, with 8 merozoites are more frequent than Type II meronts (Fig. 7). Gamogonial stages include abundant macrogamonts and macrogametes $(2.8-4.4 \times 2.4-4 \mu \mathrm{m})$ (Figs. 8 to 10$)$ and rare microgamonts $(3.07-3.3 \times 2.6-2.7 \mu \mathrm{m})$ (Figs. 8 \& 9). Macrogamonts with amylopectin granules evidenced by PAS staining (Fig. 10).

Type host. Scophthalmus maximus L.

Prevalence of infection. Prevalences in stocks variable according to origin and fish age, with maximum values (up to $100 \%$ ) observed in young fish (4 to $100 \mathrm{~g}$ ).

Locality. The parasite was detected in cultured turbot from fish farms in different sites in NW Spain (Atlantic Ocean).

Location in host. Intracellular, predominantly in the intestinal epithelium, seldom in epithelial cells of the stomach mucosa. Merogonial and gamogonial stages usually located in extracytoplasmic position within epithelial cells, whereas zygotes and oocysts located mainly in the basal portion of the epithelium.

Sporulation. Endogenous. Fully sporulated oocysts detected in the intestinal epithelium and intestinal lumen, as well as in faeces. Occurrence in stomach epithelium very rare.

Material deposited. Histological sections deposited in the Museo Nacional de Ciencias Naturales, CSIC (Madrid, Spain): Colección Invertebrados; holotype and paratype acquisition numbers are MNCN 35.02/21 and MNCN 35.02/22, respectively.

Etimology. Species named after its type host, Scophthalmus maximus.

\section{Ultrastructural observations}

All stages were located within a parasitophorous vacuole (PV) originating from the host, and initially formed on the microvillar surface of the epithelial cells.
The youngest stages observed were trophozoites already enveloped by the PV, which had retained rudimentary microvilli in the outermost membrane. These were presumably transitional stages between sporozoites and multinucleated meronts (Figs. 11 \& 12). At the contact zone of the parasite and the host cell, an electron-dense membrane was observed, just beneath the point at which the parasite plasmalemma invaginated, forming the abundant convolutions of the typical feeder-organelle (Fig. 13). The junction zone with the host-cell cytoplasm contained numerous parallel microfibrils, which joined perpendicular to the outer band (Fig. 13).

Maturing trophozoites or initial meronts had a single nucleus. Packed ribosomes and vacuoles appeared in their cytoplasm. In more advanced meronts, the nucleus underwent several divisions. Thus, some meronts with developing or fully developed merozoites were also detected (Figs. 11 to 13). Merozoites were elongated with a nucleus containing abundant heterochromatin, and some electron-dense bodies. The meront residuum was detectable upon maturity, at which time the fully formed merozoites had separated from it. The meronts observed seemed to belong to the first generation (Figs. 11 \& 12).

Gametogenesis stages were also located in an extracytoplasmic position. Maturing macrogametes (Figs. 12 to 14) contained electron-dense bodies (most of them peripheral), a nucleus and some vacuoles. Microgamonts were rarely seen. A maturing microgamont was detected in the sections, with 7 nuclei at the section level (Fig. 15).

Further developmental stages were intra-epithelial. Zygotes were not observed, but some early oocysts appeared among the cellular debris, usually in the epithelium, and rarely in the sub-epithelial connective tissue. Sporulated oocysts contained 4 naked sporozoites and a residual body with amylopectin granules and sometimes an electron-dense granule, probably lipidic (Fig. 16). Sporozoites had a pellicle comprised of 2 bilayered membranes, the inner membrane being more electron-dense (Figs. 17 \& 18). Polar rings and 1 rhoptry were detected in longitudinal sections of the apical end (Fig. 19). The nucleus was generally located in the posterior part of the body. The cytoplasm was densely packed with ribosomes, and contained some electron-dense bodies and abundant membranebound micronemes; the latter occupied most of the sporozoite even up to the nucleus (Fig. 16). A large mitochondrion, bound by a double bilayered membrane and located in the nuclear vicinity, was detected in several sporozoites. Scant cristae, mostly tubular, could be seen in the mitochondrion, as well as ribosomes and some electron-dense inclusions (Figs. 17 \& 18). Some microtubules were visible near the inner membrane layer (Fig. 17). 

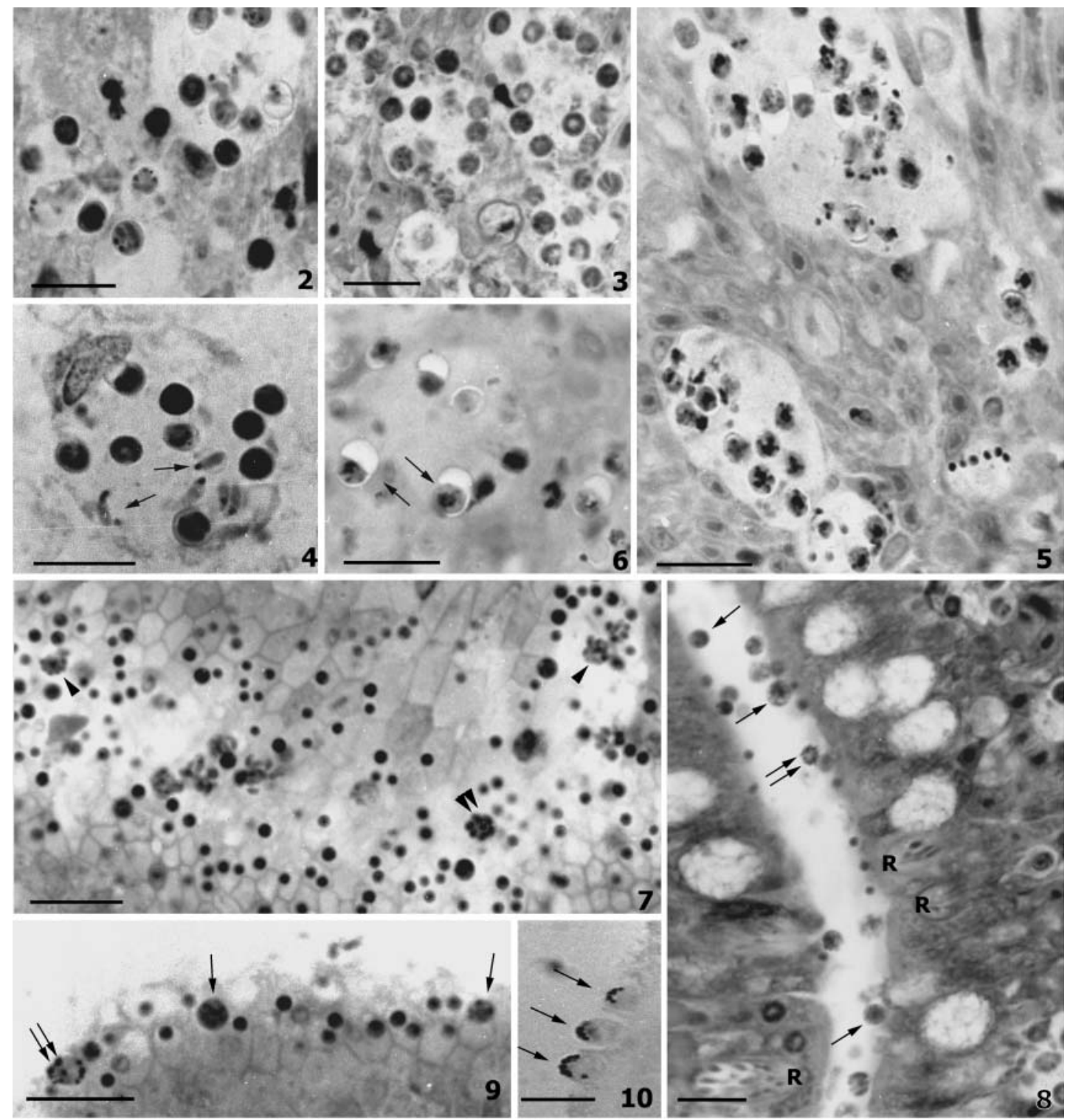

Figs. 2 to 10. Cryptosporidium scophthalmi. Photomicrographs of parasite from histological sections of Scophthalmus maximus resin-embedded intestines. Figs. 2 to 4 . Groups of oocysts in different stages of sporulation. Some sporozoites have been released from the oocysts (arrows in Fig. 4). Figs. 5 \& 6. PAS-stained groups of oocysts. PAS-positive oocyst residuum consisting of irregular amylopectin granules is visible; some oocysts are releasing sporozoites through open suture in Fig. 6 (arrows). Figs. 7 to 10. Merogonial and gamogonial stages; note abundant trophozoites, merozoites, Type I meronts (arrowhead) and Type II meronts (double arrowheads) in Fig. 7. Figs. 8 to 10. Gamogonial stages; with macrogamonts (arrows, Figs. 8 to 10) and microgamonts (double arrows, Figs. 8 \& 9) visible; R: rodlet cells. Staining = toluidine blue (Figs. 2 to 4,7 \& 8), Giemsa (Fig. 9) and PAS (Figs. 5, $6 \& 10$ ). (All scale bars $=10 \mu \mathrm{m}$ )

Oocysts were bounded by a wall of varying thickness, according to the oocyst type. Thin-walled oocysts (Figs. 16 \& 20) had a double membrane. Thick-walled oocysts had an outer wall and an inner wall (with a particulate internal structure) separated by an electronlucent space (Figs. 21 \& 22). In both thin- and thickwalled oocysts, a suture was occasionally observed (Figs. 20 \& 22, respectively).

\section{Clinical signs and histopathology}

Prevalence of Cryptosporidium scophthalmi reached $100 \%$ in juvenile fish, which also presented very high infection intensities. In larger fish (up to $400 \mathrm{~g}$ ) prevalence was lower and rarely exceeded 10\%. Fish weighing $>400 \mathrm{~g}$ were seldom infected, and then always at low intensity. The largest fish found para- 


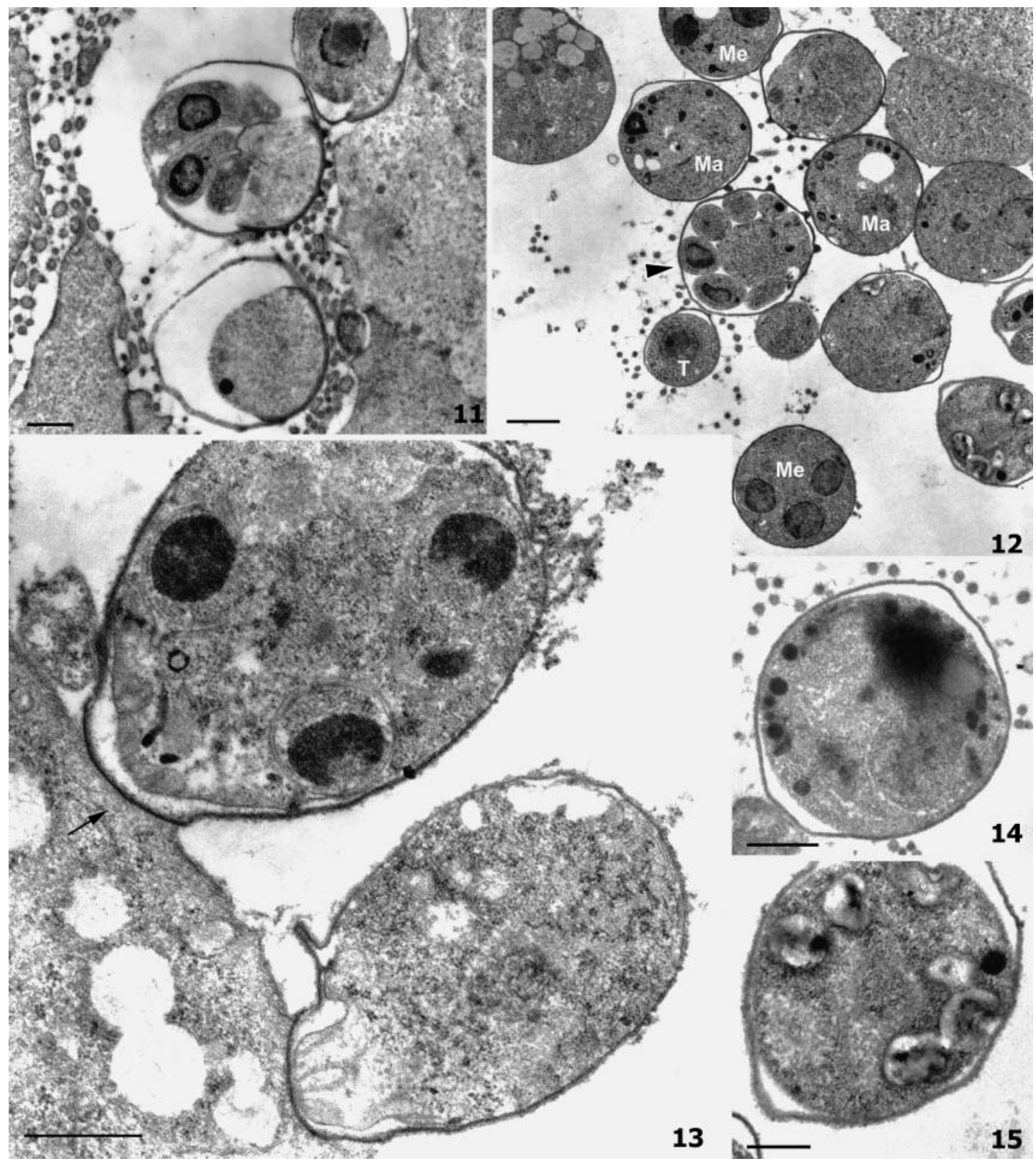

Figs. 11 to 15. Cryptosporidium scophthalmi. TEM micrographs of merogonial and gamogonial stages. Fig. 11. Trophozoites and meront; divided merozoites are still associated with meront's residuum. Fig. 12. Cross-section at level of microvilli surface showing trophozoite $(\mathrm{T})$, dividing meronts (Me), divided meront with 6 merozoites on section plane (arrowhead), and some early macrogamonts (Ma). Fig. 13. 2 meronts with feeding organelle visible; top meront has initiated division process and displays 3 nuclei; arrowhead indicates feeding organelle and electron-dense remnants of sub-pellicular membrane; note parallel microfribils in junction zone (arrow) and vacuolation of host-cell cytoplasm. Fig. 14. Macrogamont with electron-dense inclusions and nucleus. Fig. 15. Early microgamont. (Scale bars $=1 \mu \mathrm{m}$ in Figs. 11 to $12 \& 14,0.5 \mu \mathrm{m}$ in Figs. 13 \& 15)

sitised belonged to the offshore cage group (mean weight $1500 \mathrm{~g}$, prevalence $15 \%$, intensity very light). Upon necropsy, coelomic viscera were generally normal, except for some fish that showed intestinal distension arising from mucous intestinal contents and gas. In Giemsa-stained mucosal scrapings, oocysts showing 'metachromasia' were detected.
Parasitic stages were mostly present in the distal half of the intestine, mainly in the rectum. Infected intestines displayed a variable number of extracytoplasmic stages lining the epithelium. The simultaneous presence of intra-epithelial sporogonic stages was very frequent (Figs. 23, 25 \& 26). In severely affected fish, clusters of oocysts occupying wide vacuolated areas of 


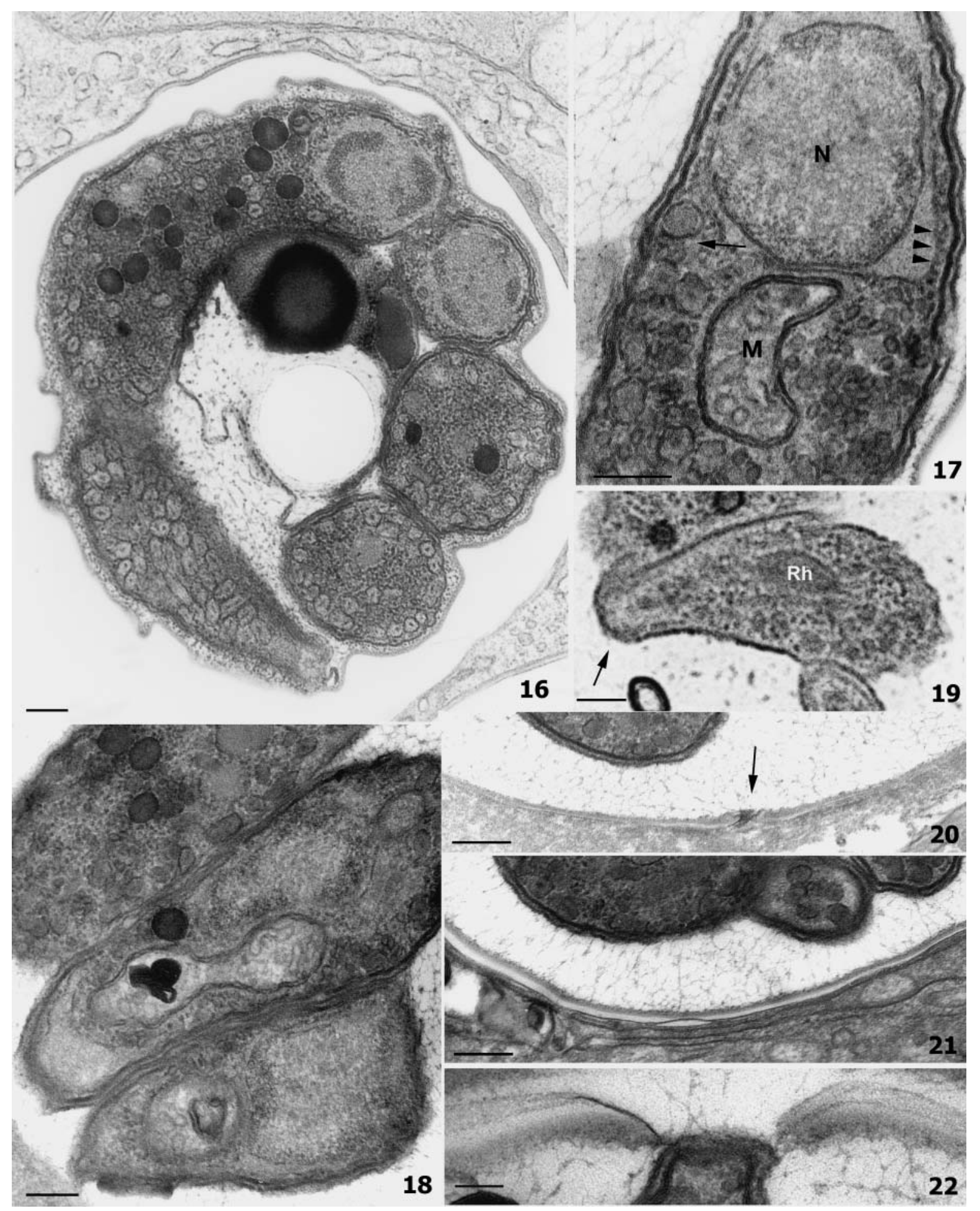

Figs. 16 to 22. Cryptosporidium scophthalmi. TEM micrographs of oocysts. Fig. 16. Sporulated thin-walled oocyst; 1 curved sporozoite in longitudinal section (note abundant micronemes and several electron-dense bodies), 3 cross-sectioned sporozoites, and oocyst residuum are visible. Fig. 17. Detail of posterior part of sporozoite showing 3-layered pellicle, microtubules (arrowheads), nucleus (N) and a mitochondrion $(\mathrm{M})$; note micronemes near nucleus level (arrow). Fig. 18. Detail of sporozoites, showing mitochondria of different shapes, harbouring scant tubular cristae and inclusions. Fig. 19. Detail of apical end of sporozoite with 1 rhoptry (Rh); apical rings are barely visible (arrow). Fig. 20. Detail of suture line (arrow) of thin-walled oocyst. Figs. $21 \& 22$. Thick-walled oocysts. (All scale bars $=0.2 \mu \mathrm{m}$ ) 
the intestinal epithelium were observed (Figs. 26 to 28). Scant oocysts were observed free in the intestinal lumen, sometimes being released with remnants of epithelial cells (Fig. 4).
Infected intestines showed different degrees of damage, usually correlating with the infection intensity. In weak infections, extracytoplasmic stages predominated and were scattered on the intestinal surface pro-

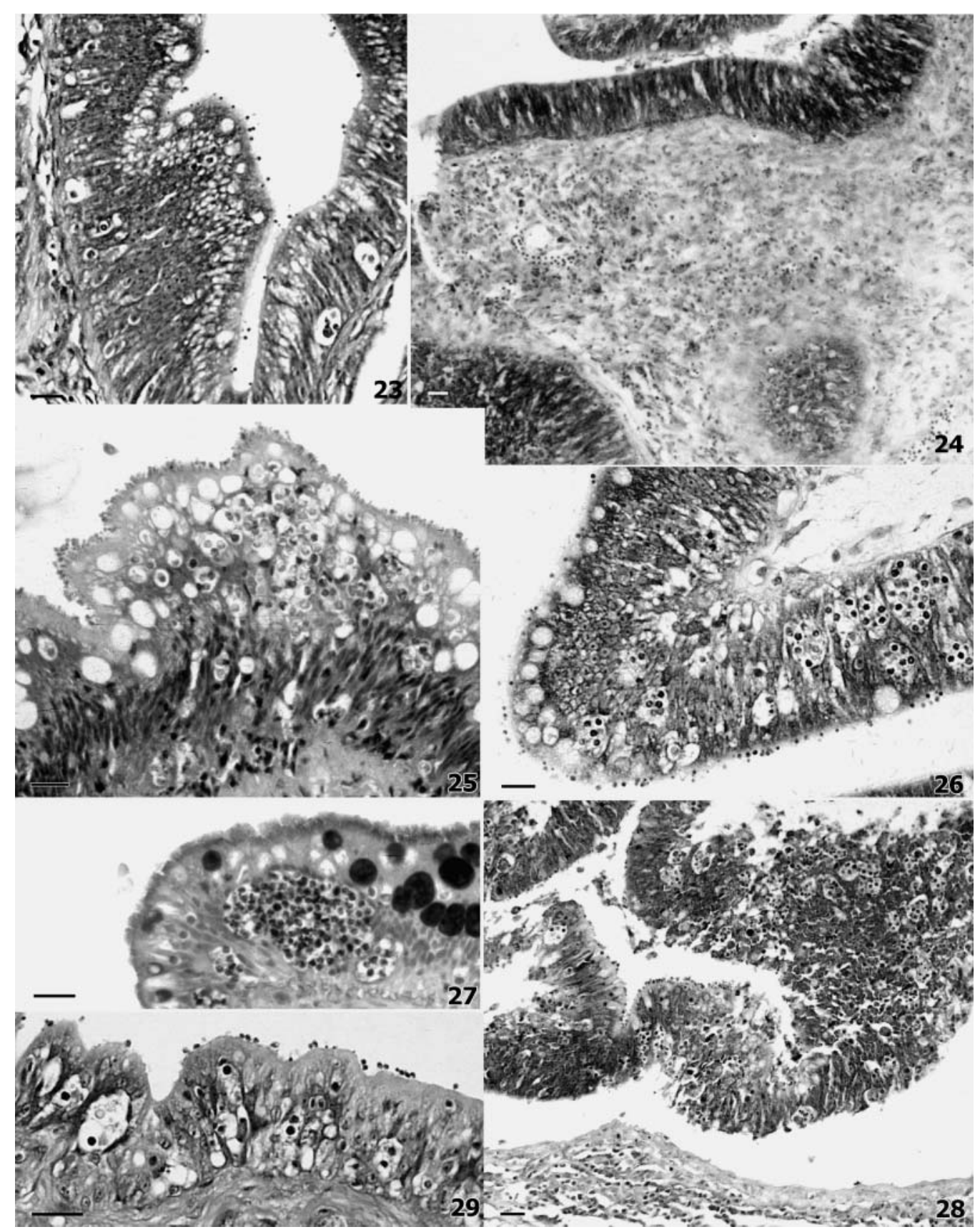

Figs. 23 to 29. Cryptosporidium scophthalmi. Photomicrographs of parasite from histological sections of Scophthalmus maximus paraffin-embedded intestines (Figs. 23 to 28) and stomach (Fig. 29). Figs. 23 \& 24. Slight tissue damage during weak infections, consisting of vacuolation (Fig. 23) and inflammatory reaction with leucocyte infiltration (Fig. 24). Fig. 25. Mild histopathological effects in intestine at medium infection level of both extracytoplasmic and sporogonic stages. Figs. 26 to 28 . Severely infected intestines with characteristic groups of oocysts occupying wide zones of epithelium and simultaneous presence of extracytoplamic stages (Figs. 26 \& 28). Fig. 29. Slight infection in stomach epithelium. Staining = H\&E (Figs. 23 to 26, 28 \& 29) and PAS (Fig. 27). 


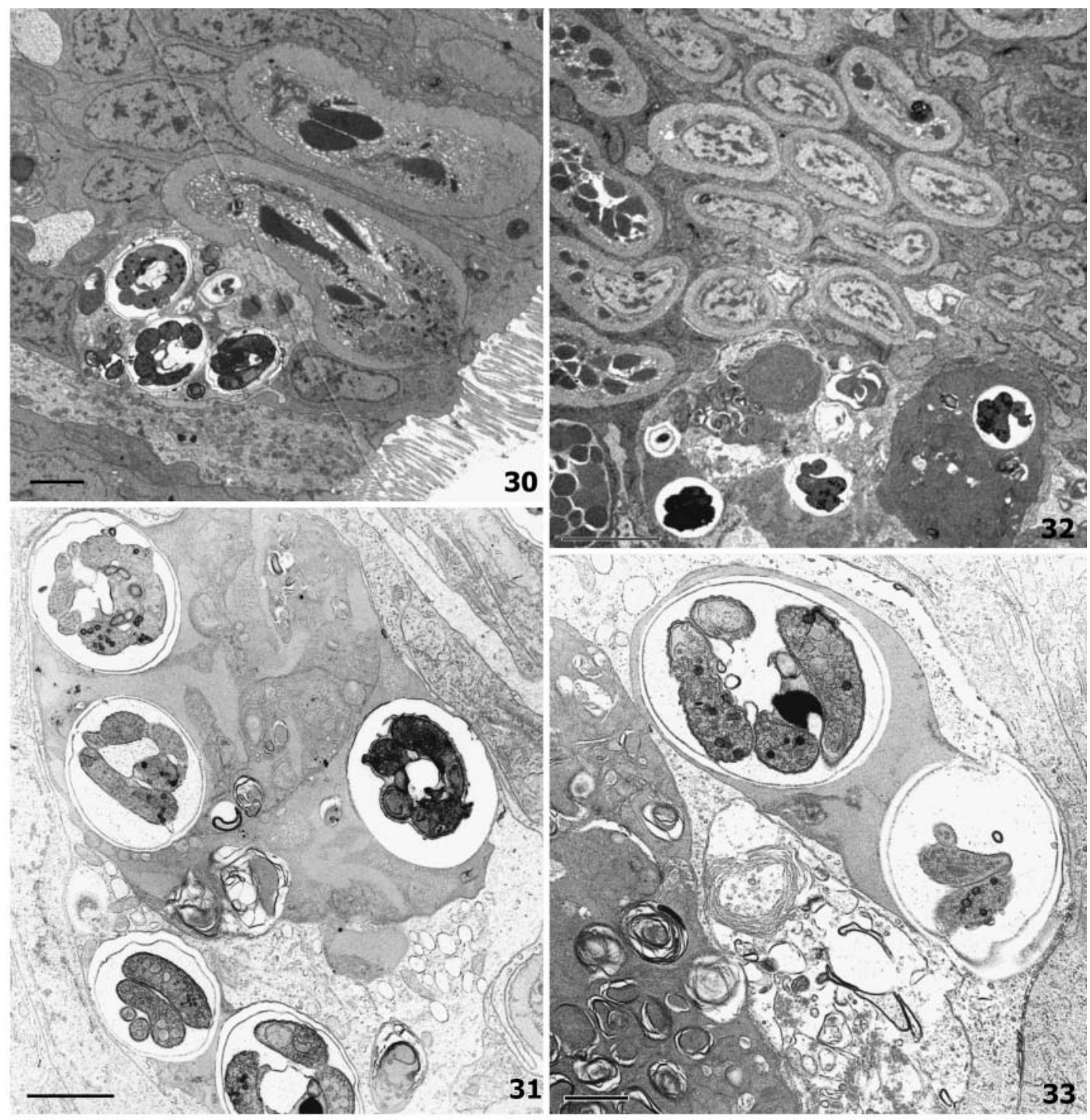

Figs. 30 to 33. Cryptosporidium scophthalmi. TEM micrographs of parasite infecting Scophthalmus maximus intestine, showing different degrees of histopathological damage. Note association of rodlet cells with parasitic stages (Figs. 30 \& 32), and degeneration and vacuolation of host-tissue remnants in vicinity of oocyst groups (Figs. 31 \& 33). (Scale bars $=2 \mu \mathrm{m}$ in Figs. $30 \& 31,5 \mu \mathrm{m}$ in Fig. 32, $1 \mu \mathrm{m}$ in Fig. 33)

ducing slight or no obvious tissue lesions (Fig. 23); the lamina propria was infiltrated by a moderate to large number of mononuclear cells (Fig. 24). In moderate infections, stages were spread over the intestinal surface, but some intra-epithelial sporogonial stages were also visible, producing mild intestinal lesions (Fig. 25). In massive infections, most of the epithelial surface was covered by different merogonial and gamogonial stages and groups of intra-epithelial oocysts were abundant, producing severe intestinal lesions (Figs. 26 to 28). In such advanced infections, many epithelial cells were distended by large vacuoles containing clusters of oocysts, which distorted the normal mucosal architecture and could lead to desquamation of the intestinal mucosa. In most cases, these oocyst clusters were surrounded by a membrane together with remnants of the host cell, whose nucleus appeared displaced to one side. In these heavy infections, the inflammatory response (involving mainly lymphocytes and macrophages) could be severe. Exocytosis of some lymphocytes into the epithelium was common when epithelial lesions were severe. The abundance of rodlet cells in infected epithelia was also evident (Fig. 8). Numerous goblet cells were also observed. 


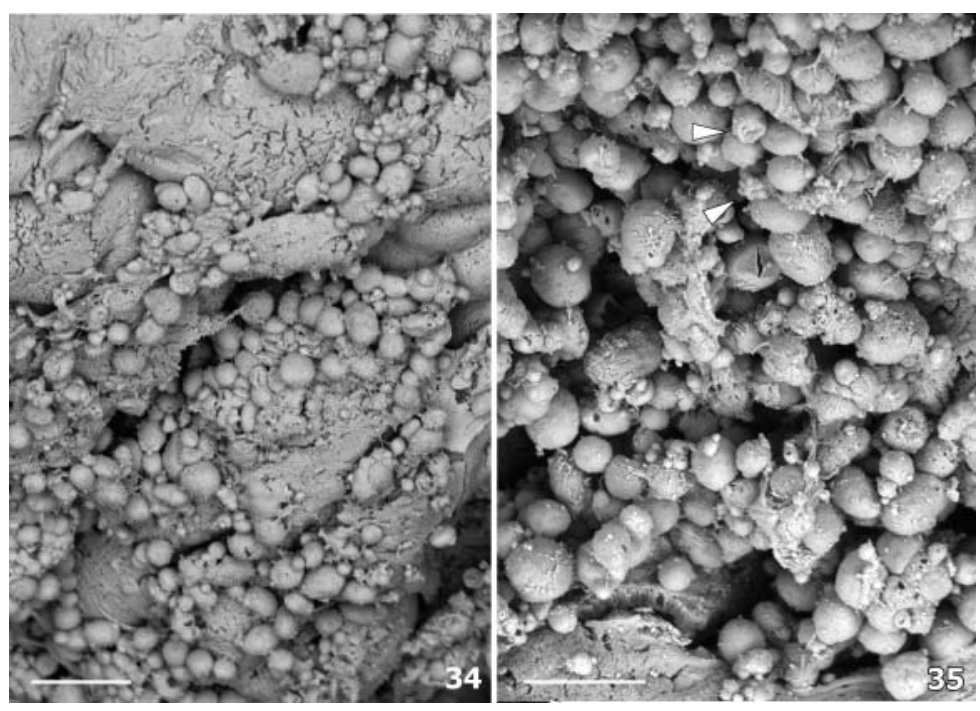

Figs. 34 \& 35. Cryptosporidium scophthalmi. SEM micrographs of parasite infecting Scophthalmus maximus intestine. Fig. 34. Mild infection, showing both invaded and parasite-free areas of epithelial surface. Fig. 35. Severe infection with most of epithelial surface covered by parasite stages; note meronts containing or releasing merozoites (arrowheads). (Scale bars $=50 \mu \mathrm{m}$ in Fig. 34, $20 \mu \mathrm{m}$ in Fig. 35)

Parasitic stages were seldom found in the gastric mucosa (only 7 fish were parasitised in this tissue), and they produced no or very slight lesions. Merogonial stages were visible on the epithelial surface
(Fig. 29), but the parasite was not present in the glandular cells.

\section{Ultrastructural histopathology}

No important damage, apart from a certain vacuolation of the invaded host cell, was observed when only extracytoplasmic stages were present (Fig. 13), in contrast to epithelia infected by sporogonic stages. The characteristic groups of oocysts surrounded by debris of host cells were usually found within the epithelium and seldom in the sub-epithelial connective tissue. The degree of damage to epithelial tissue was variable. In some cases, oocysts appeared in the vicinity of rodlet cells, but with no evident damage to the adjoining tissue (Fig. 30). In more advanced infection stages, groups of oocysts together with remnants of the infected host cells occupied large vacuolated spaces (Fig. 31). The remnants of parasitised cells degraded progressively, and oocysts were visible embedded in the degenerated cell matrix, which became increasingly electron-dense, and was sometimes observed in the vicinity of numerous rodlet cells (Fig. 32). In a final phase, only very electron-dense residual material (with abundant membrane remnants, myelinic bodies and

Table 1. Cryptosporidium scophthalmi. Comparison with other piscine Cryptosporidium species. Different superscript letters indicate statistically significant differences ( $\mathrm{p} \leq 0.05)$. Length, width: range $(\bar{x} \pm \mathrm{SD})$ (if available). SI: shape index (length/width ratio); na: not available

\begin{tabular}{|c|c|c|c|c|c|c|c|c|}
\hline \multirow{2}{*}{ Species } & \multirow{2}{*}{ Host(s) } & \multirow{2}{*}{$\begin{array}{l}\text { Geographic } \\
\text { origin }\end{array}$} & \multirow{2}{*}{$\begin{array}{l}\text { Infection } \\
\text { site }\end{array}$} & \multirow[b]{2}{*}{$\mathrm{n}$} & \multicolumn{3}{|c|}{ _ Oocyst measurements } & \multirow{2}{*}{ Source } \\
\hline & & & & & $\begin{array}{l}\text { Length } \\
(\mu \mathrm{m})\end{array}$ & $\begin{array}{l}\text { Width } \\
(\mu \mathrm{m})\end{array}$ & SI & \\
\hline $\begin{array}{l}\text { Cryptosporidium } \\
\text { nasoris }\end{array}$ & Naso lituratus & Indiana, USA & Intestine & & 3.6 & na & na & Hoover et al. (1981) \\
\hline Cryptosporidium sp. & $\begin{array}{l}\text { Sciaenops } \\
\text { ocellatum }\end{array}$ & Lousiana, USA & Stomach & & 7 & 4 & na & Camus \& López (1996) \\
\hline $\begin{array}{l}\text { Piscicryptosporidium } \\
\text { reichenbachklinkei }\end{array}$ & $\begin{array}{l}\text { Trichogaster } \\
\text { leeri }\end{array}$ & SE Asia, Israel & Stomach & & $2.4-3.18$ & $2.4-3$ & na & Paperna \& Vilenkin (1996) \\
\hline $\begin{array}{l}\text { Piscicryptosporidium } \\
\text { cichlidis }\end{array}$ & $\begin{array}{l}\text { Oreochromis } \\
\text { spp. }\end{array}$ & Israel & Stomach & & $\begin{array}{c}4-4.7 \\
(4.3 \pm 0.46)\end{array}$ & $\begin{array}{c}2.5-3.5 \\
(3.2 \pm 0.64)\end{array}$ & $\begin{array}{l}\text { na } \\
\text { na }\end{array}$ & Paperna \& Vilenkin (1996) \\
\hline $\begin{array}{l}\text { Piscicrypto- } \\
\text { sporidium sp. }\end{array}$ & Sparus aurata & Red Sea, Israel & Stomach & 32 & $3.1 \pm 0.5$ & na & na & Paperna \& Vilenkin (1996) \\
\hline \multirow[t]{2}{*}{$\begin{array}{l}\text { Cryptosporidium } \\
\text { molnari }\end{array}$} & Sparus aurata & $\begin{array}{l}\text { Cantabric, } \\
\text { Mediterranean, } \\
\text { South Atlantic, } \\
\text { Spain }\end{array}$ & Stomach & 57 & $\begin{array}{l}4.64 \pm 0.29^{\mathrm{a}} \\
(4.11-5.46)\end{array}$ & $\begin{array}{l}4.13 \pm 0.26^{\mathrm{a}} \\
(3.63-4.85)\end{array}$ & $\begin{array}{l}1.13 \pm 0.07^{\mathrm{b}} \\
(1-1.37)\end{array}$ & $\begin{array}{l}\text { Alvarez-Pellitero \& } \\
\text { Sitjà Bobadilla (2002) }\end{array}$ \\
\hline & $\begin{array}{l}\text { Dicentrarchus } \\
\text { labrax }\end{array}$ & $\begin{array}{l}\text { Cantabric, } \\
\text { Mediterranean, } \\
\text { South Atlantic, } \\
\text { Spain }\end{array}$ & Stomach & 64 & $\begin{array}{l}4.29 \pm 0.2^{\mathrm{b}} \\
(3.84-4.85)\end{array}$ & $\begin{array}{l}3.99 \pm 0.23^{b} \\
(3.52-4.64)\end{array}$ & $\begin{array}{l}1.08 \pm 0.05^{\mathrm{a}} \\
(1-1.19)\end{array}$ & $\begin{array}{l}\text { Alvarez-Pellitero \& } \\
\text { Sitjà Bobadilla (2002) }\end{array}$ \\
\hline $\begin{array}{l}\text { Cryptosporidium } \\
\text { scophthalmi }\end{array}$ & $\begin{array}{l}\text { Scophthalmus } \\
\text { maximus }\end{array}$ & $\begin{array}{l}\text { North Atlantic, } \\
\text { Spain }\end{array}$ & Intestine & 49 & $\begin{array}{c}4.44 \pm 0.34^{\mathrm{c}} \\
(3.7-5.03)\end{array}$ & $\begin{array}{l}3.91 \pm 0.41^{\mathrm{b}} \\
(3.03-4.69)\end{array}$ & $\begin{array}{l}1.14 \pm 0.06^{\mathrm{b}} \\
(1.05-1.34)\end{array}$ & Current paper \\
\hline
\end{tabular}


vacuolated spaces) was visible near the oocysts (Fig. 33), even when oocysts had been completely destroyed or released.

Under the SEM, parasites were detectable at low magnification as spherical bodies of various sizes distributed over the surface of the intestinal villi. Comparison of infected and uninfected parts of the intestine, revealed destruction of the epithelium and various degrees of damage to the mucosa folds in infected areas (Fig. 34). In heavy infections, parasitic stages covered most of the epithelial surface (Fig. 35). Trophozoites or initial meronts, as well as advanced meronts (sometimes releasing merozoites) and gamogonial stages were distinguishable (Fig. 35). Craters were visible on the villous surface as black, sharply demarcated circles surrounded by a white halo. Some microvilli remnants covering the parasitic stages were also detected, although in most cases the microvilli were lost.

\section{DISCUSSION}

\section{Taxonomy}

Cryptosporidium scophthalmi presents most of the features characteristic of the genus Cryptosporidium, namely the extracytoplasmic development of merogonial and gamogonial stages, the absence of sporocysts, and the presence of 4 sporozoites. However, as in other piscine Cryptosporidium species, sporulation takes place deep in the epithelium, in contrast to species from other host types. The genus Piscicryptosporidium was created by Paperna \& Vilenkin (1996) to include some piscine species, based mainly on their intra-epithelial sporulation. As stated in the Cryptosporidium molnari description (Alvarez-Pellitero \& Sitjà-Bobadilla 2002), we agree with Morgan et al. (1999), who pointed out the lack of biological and genetic support for the validity of the genus Piscicryptosporidium. Therefore, as in the case of C. molnari, we ascribe the new parasite species found in turbot to the genus Cryptosporidium.

Table 1 compares Cryptosporidium scophthalmi with other piscine Cryptosporidium species for which measurements are available. A statistical comparison was possible only with $C$. molnari, as complete data are not available for the remaining species. As reported earlier (Alvarez-Pellitero \& Sitjà-Bobadilla 2002), there are 4 piscine species described from an intestinal location: C. nasoris from Naso lituratus, and 3 unnamed species from Cyprinus carpio, Lates calcarifer and Plecostomus spp. (the latter can occasionally be found in the stomach). The original description of $C$. nasoris is incomplete, referring to some merogonial and gamogonial stages and also a 'round organism $(3.6 \mu \mathrm{m})$ consistent with a developing oocyst' (Hoover et al. 1981). The size of the latter is smaller than that of Cryptosporidium scophthalmi in the present study. Interestingly, in an exhaustive review of the genus O'Donoghue (1995) gave detailed oocyst dimensions for a species referred to as C. nasorum, contrasting with the vague, original description of $C$. nasoris given by Hoover et al. (1981). In his review, O'Donoghue (1995) cited Landsberg \& Paperna (1986) as the source of the C. nasorum measurements, but their study actually presented a description of a Cryptosporidium species from the stomach of a cichlid fish, subsequently identified as Piscicryptosporidium cichlidis by Paperna \& Vilenkin (1996). Notwithstanding, further reviews of the genus (Fayer et al. 2000) refer to a C. nasorum with similar measurements to those reported by O'Donoghue (1995). We consider worthy of note that an incompletely described species (C. nasoris), has appeared in different reviews of the genus as the only valid species of piscine Cryptosporidium, with a modified name (nasorum versus nasoris) and with morphometric data of another Cryptosporidium species.

The remaining piscine species, all parasitising the stomach (Cryptosporidium molnari is seldom found in the intestine), differ in size and shape from our species. Piscicryptosporidium reichenbachklinkei oocysts are much smaller and almost spherical, and those of $P$. cichlidis are slightly smaller and more elongated. $C$. molnari is closer in size to the species from turbot, although some differences do exist: C. scophthalmi oocysts are significantly smaller $(p \leq 0.05)$ than those of C. molnari from gilthead sea bream, its type host, although their shape indexes are similar. However, the shape index and length of C. scophthalmi and C. molnari from sea bass are significantly different ( $\mathrm{p} \leq 0.05)$. In addition, the size of merogonial and gamogonial stages are smaller in C. scophthalmi than in C. molnari. Our TEM observations demonstrated more abundant membrane-bound micronemes, and more frequent mitochondria, with tubular cristae, in sporozoites of $C$. scophthalmi.

Other features, besides oocyst morphology must be considered when differentiating valid species of Cryptosporidium. Besides the recent genetic studies, several biological aspects, such as organ location, hostspecificity, and pathogenicity, can help determine which are species and which are variants of the same species (Xiao et al. 2002). Although genetic data are not yet available for any piscine species, some biological data, as organ location and host-specificity, support the designation of C. scophthalmi as a new species. For instance, the closest species, C. molnari, has a typically gastric location, whereas C. scophthalmi is an intestinal parasite. Some phylogenetic analyses of Crypto- 
sporidium spp. support the biological data: thus, $C$. muris and its closest relative $C$. serpentis (both parasitising the stomach) diverge from other Cryptosporidium spp. which infect the small intestine or the respiratory tract (Morgan et al. 1999).

The host species could also be of taxonomic relevance, considering the distant ecologic and phylogenetic relationship of turbot to gilthead sea bream and sea bass. In support of this is the observation that turbot reared in a re-circulation system in which Cryptosporidium molnari-parasitised sea bass and gilthead sea bream were also cultured were never infected by C. molnari (F. Padrós \& C. Aguilera unpubl. obs.). Recent multilocus genetic characterization indicates that host adaptation is a general phenomenon in the genus Cryptosporidium and contributes to the parasites genetic heterogeneity (Xiao et al. 2002). The geographical location of fish parasitised by C. molnari and C. scophthalmi also differs (the latter is present only in Atlantic waters). However, the possible inadequacy of turbot as a host for C. molnari can only be ascertained by transmission experiments.

Therefore, the differences of the current species from the known Cryptosporidium species justify its ascription to a new species. We also plan to perform genetic studies to compare this species with other Cryptosporidium spp.

\section{Ultrastructural aspects}

Our ultrastructural study of Cryptosporidium scophthalmi demonstrated the similarity of its main characteristics with those of other Cryptosporidium species. The structure of the host/parasite contact zone and the feeder organelle resemble those described for other Cryptosporidium species (Fayer et al. 1997), with an electron-dense layer or outer bands with perpendicularly interwoven microfribils or microfilaments, as in Piscicryptosporidium reichenbachklinkei (Paperna \& Vilenkin 1996) and C. molnari (Alvarez-Pellitero \& Sitjà-Bobadilla 2002). These structures are perhaps equivalent to the tubular like structures reported by Beyer et al. (2000) for C. parvum, or the indented border of C. muris (Uni et al. 1987). The electron-dense border of the host cell in contact with the parasite was observed even in relatively advanced stages, as it occurs in several Cryptosporidium species (but not in C. molnari). The sub-pellicular membrane was only observed in some sections of merozoites, as electrondense structures. The appearance of rhoptries and micronemes in merogonial stages of C. scophthalmi was similar to that found in other Cryptosporidium species. Details of gametogenesis or initial stages of sporulation could not be observed with TEM.
The structure of sporozoites does not differ substantially from that described for other Cryptosporidium spp. In the scant longitudinal sections of the apical part of sporozoites examined, 1 rhoptry was detected; this is in accordance with the observations of Tetley et al. (1998) and Petry \& Harris (1999) for C. parvum. Remarkable was the abundance of membrane-bound micronemes in C. scophthalmi, mainly in the anterior third of the body, but also in the posterior part. In $C$. parvum, Tetley et al. (1998) also found abundant micronemes, but all were located apically.

A mitochodrion was clearly identifiable in the sporozoites, providing evidence of the presence of this organelle in another Cryptosporidium species besides $C$. parvum (Moriya 1989, Riordan et al. 1999), C. muris (Uni et al. 1987) and the piscine C. molnari (Alvarez-Pellitero \& Sitjà-Bobadilla 2002). The significance and controversy of such an organelle in Cryptosporidium spp. has been discussed by Alvarez-Pellitero \& Sitjà-Bobadilla (2002). In C. scophthalmi, tubular cristate mitochondria were found, as in C. muris (Uni et al. 1987), but in contrast to $C$. molnari and C. parvum (Riordan et al. 1999) in which acristate mitochondria were reported.

Both thick- and thin-walled oocysts were detected in Cryptosporidium scophthalmi. The oocyst wall had a structure similar to that of other species. The suture line was seldom observed, but when present seemed to comprise a simple juxtaposition of the sutural borders.

\section{Pathological effects and course of infection}

Clinical signs in fish infected by Cryptosporidium spp. have been reported only in the masked unicornfish (naso tang) Naso lituratus (Hoover et al. 1981), in freshwater angelfish (Gratzek 1993), in catfish (Muench \& White 1997), and (rarely) in gilthead sea bream infected by C. molnari (Alvarez-Pellitero \& Sitjà-Bobadilla 2002).

In turbot cryptosporidiosis, clinical signs were rarely observed, although a clear effect of the infection on fish growth was noted in several groups of heavily infected juvenile fish (F. Padrós unpubl. obs.). In addition, histopathological damage was fairly extensive, especially for heavy infections. Epithelial destruction was more extensive than in other piscine species, such as C. molnari (Alvarez-Pellitero \& Sitjà-Bobadilla 2002), and the release of sporozoites from oocysts in vacuolated epithelial zones (which probably increases the possibility of re-infection) was also more frequent than in C. molnari.

The histopathological effects of Cryptosporidium scophthalmi resemble those described for other intestinal Cryptosporidium species: villus atrophy and fusion, the degeneration and sloughing of individual entero- 
cytes, and the shortening of microvilli (Current 1989, Fayer et al. 1997). Leucocyte inflammatory infiltration, similar to that in turbot, has been described in cryptosporidioses of both piscine (Camus \& López 1996) and non-piscine (Koudela \& Modrý 1998, Laurent et al. 1999) hosts. This contrasts with C. molnari infections, for which no cellular reaction was detected. The abundant rodlet cells found in infected turbot may play a role in the cellular reaction. These enigmatic cells have been observed in tissues of marine and freshwater teleosts. Although their origin and function remain controversial, some authors attribute to them a role in the host's reaction against pathogenic organisms (Leino 1996, Reite 1997, Dezfuli et al. 1998), and more specifically in the inflammatory response observed in certain parasitoses (Dezfuli et al. 2000).

Thus, although turbot cryptosporidiosis does not seem to produce important clinical effects or mortalities, intestinal epithelial damage could contribute to poor food conversion, weakness, and increased susceptibility to other infections or interactions with other pathogens, as described in other cryptosporidioses (de Graaf et al. 1999, Enemark et al. 2003). The role of cryptosporidiosis in the appearance and course of another important turbot parasitosis induced by the intestinal myxosporean Enteromyxum scophthalmi (Branson et al. 1999, Palenzuela et al. 2002) remains to be elucidated. Concomitant infections are not very frequent, but the appearance of myxosporidiosis mainly occurs in an age class that has usually overcome the cryptosporidiosis. Epidemiological studies of these infections are under way (P. Alvarez-Pellitero et al. unpubl. obs.) to clarify this. The importance of concomitant infections and immunocompromised situations in the pathology of Cryptosporidium spp. is well documented for humans and farm animals (Tzipori \& Ward 2002, Enemart et al. 2003). Besides E. scophthalmi, other turbot parasites such as the microsporidian Tetramicra brevifillum may appear in concomitant infections with C. scophthalmi (Alvarez-Pellitero et al. unpubl. obs.) and a synergistic pathological effect in these mixed or sequential infections cannot be disregarded.

Acknowledgements. Funding for this study was provided by the EU and the Spanish Ministerio de Ciencia y Tecnología through research grants FEDER 1FD97-0679 and AGL20012241. Additional support was obtained from Stolt Sea Farm S. A. We are thankful to technical services at the Universities of Barcelona and Valencia, to J. Monfort from IATS, and to M. C. Carreira Valle from the School of Veterinary Medicine of Lugo (University of Santiago) for assistance in processing electron and light microscopy samples.

\section{LITERATURE CITED}

Alvarez-Pellitero P, Sitjà-Bobadilla A (2002) Cryptosporidium molnari n. sp. (Apicomplexa: Cryptosporidiidae) infecting two marine fish species, Sparus aurata L. and Dicentrarchus labrax L. Int J Parasitol 32:1007-1021

Beyer TV, Svezhova NV, Sidorenko NV, Khohlov SE (2000) Cryptosporidium parvum (Coccidia, Apicomplexa): some new ultrastructural observations on its endogenous development. Eur J Protistol 36:151-159

Branson E, Riaza A, Alvarez-Pellitero P (1999) Mxosporean infection causing intestinal disease in farm turbot, Scophthalmus maximus (L.) (Teleostei: Scophthalmidae). J Fish Dis 22:395-400

Camus AC, López MK (1996) Gastric cryptosporidiosis in juvenile red drum. J Aquat Anim Health 8:167-172

Current WL (1989) Cryptosporidium spp. In: Walzer PD, Genta RM (eds) Parasitic infections in the compromised host. Marcel Dekker, New York, p 281-341

de Graaf DC, Vanopdenbosch E, Ortega-Mora LM, Abbassi $\mathrm{H}$, Peeters JE (1999) A review of the importance of cryptosporidiosis in farm animals. Int J Parasitol 29:1269-1287

Dezfuli BS, Capuano S, Manera M (1998) A description of rodlet cells from the alimentary canal of Anguilla anguilla and their relationship with parasitic helminths. J Fish Biol 53:1084-1095

Dezfuli BS, Simoni E, Rossi R, Manera M (2000) Rodlet cells and other inflamatory cells of Phoxinus phoxinus infected with Raphidascaris acus (Nematoda). Dis Aquat Org 43:61-69

Dillingham RA, Lima AA, Guerrant RL (2002) Cryptosporisiosis: epidemiology and impact. Microbes Infect 4: 1059-1066

Enemark HL, Bille-Hansen V, Lind P, Heegaard PMH, Vigre H, Ahrens P, Thamsborg SM (2003) Pathogenicity of Cryptosporidium parvum - evaluation of an animal infection model. Vet Parasitol 113:35-57

Fayer R, Speer CA, Dubey JP (1997) The general biology of Cryptosporidium. In: Fayer R (ed) Cryptosporidium and cryptosporidiosis. CRC Press, Boca Ratón, FL, p 1-41

Fayer R, Morgan U, Upton SJ (2000) Epidemiology of Cryptosporidium: transmission, detection and identification. Int J Parasitol 30:1305-1322

Gratzek JB (1993) Parasites associated with fresh-water tropical fishes. In: Stoskopf ME (ed) Fish medicine. Saunders, Philadelphia, PA, p 573-590

Hoover DM, Hoerr FJ, Carlton WW, Hinsman EJ, Ferguson HW (1981) Enteric cryptosporidiosis in a naso tang, Naso lituratus Bloch and Schneider. J Fish Dis 4:425-428

Koudela B, Modrý D (1998) New species of Cryptosporidium (Apicomplexa: Cryptosporidiidae) from lizards. Folia Parasitol 45:93-100

Landsberg JH, Paperna I (1986) Ultrastructural study of the coccidian Cryptosporidium sp. from stomachs of juvenile cichlid fish. Dis Aquat Org 2:13-20

Laurent F, McCole D, Eckmann L, Kagnoff MF (1999) Pathogenesis of Cryptosporidium parvum infection. Microbes Infect 2:141-148

Leino RL (1996) Reaction of rodlet cells to a myxosporean infection in kidney of the bluegill, Lepomis macrochirus. Can J Zool 74:217-225

Morgan U, Xiao L, Fayer R, Lal AA, Thompson RCA (1999) Variation in Cryptosporidium: towards a taxonomic revision of the genus. Int J Parasitol 29:1733-1751

Moriya K (1989) Ultrastructural observations on oocysts, sporozoites and oocyst residuum of Cryptosporidium muris (Strain RN66). J Osaka City Med Cent 38:177-201

Muench TR, White MR (1997) Cryptosporidiosis in a tropical freshwater catfish (Plecostomus spp.). J Vet Diagn Investig 9:87-90

O'Donoghue PJ (1995) Cryptosporidium and cryptosporidiosis in man and animals. Int J Parasitol 25:139-195 
Palenzuela O, Redondo MJ, Alvarez-Pellitero P (2002) Description of Enteromyxum scophthalmi gen. nov., sp. nov. (Myxozoa), an intestinal parasite of turbot (Scophthalmus maximus L.) using morphological and ribosomal RNA sequence data. Parasitology 124:369-379

Paperna I, Vilenkin M (1996) Cryptosporidiosis in the gourami Thrichogaster leeri: description of a new species and a proposal for a new genus, Piscicryptosporidium, for species infecting fish. Dis Aquat Org 27:95-101

Pavlásek I (1983) Cryptosporidium sp. in Cyprinus carpio Linné 1758 in Czechoslovakia. Folia Parasitol 30:248

Petry F, Harris JR (1999) Ultrastructure, fractionation and biochemical analysis of Cryptosporidium parvum sporozoites. Int J Parasitol 29:1249-1260

Reite OB (1997) Mast cells/eosinophilic granule cells of salmonids: staining properties and responses to noxious agents. Fish Shellfish Immunol 7:567-584

Riordan CE, Langreth SG, Sanchez LB, Kayser O, Keithly JS (1999) Preliminary evidence for a mitochondrion in Cryptosporidium parvum: phylogenetic and therapeutic implications. J Eukayot Microbiol 46:52S-55S

Sitjà-Bobadilla A, Alvarez-Pellitero P (2003) Experimental

Editorial responsibility: Wolfgang Körting,

Hannover, Germany transmission of Cryptosporidium molnari (Apicomplexa: Coccidia) to gilthead sea bream (Sparus aurata L.) and European sea bass (Dicentrarchus labrax L.). Parasitol Res 91:209-214

Sréter T, Varga I (2000) Cryptosporidiosis in birds - a review. Vet Parasitol 87:261-279

Tetley L, Brown SMA, McDonald V, Coombs GH (1998) Ultrastructural analysis of the sporozoite of Cryptosporidium parvum. Microbiology (Reading) 144:3249-3255

Tzipori S, Ward H (2002) Cryptosporidiosis: biology, pathogenesis and disease. Microbes Infect 4:1047-1058

Uni S, Iseki M, Maekawa T, Moriya K, Takada S (1987) Ultrastructure of Cryptosporidium muris (strain RN 66) parasitising the murine stomach. Parasitol Res 74: 123-132

Xiao L, Morgan UM, Fayer R, Thompson RCA, Lal AA (2000) Cryptosporidium systematics and implications for public health. Parasitol Today 16:287-292

Xiao L, Sulaiman I, Ryan UM, Zhou L and 5 others (2002) Host adaptation and host-parasite co-evolution in Cryptosporidium: implications for taxonomy and public health. Int J Parasitol 32:1773-1785

Submitted: January 19, 2004; Accepted: April 26, 2004 Proofs received from author(s): October 21, 2004 